\title{
PROMESSAS E LIMITES: O SISU E SUA IMPLEMENTAÇÃO NA UNIVERSIDADE FEDERAL DE MINAS GERAIS
}

\author{
Cláudio Marques Martins Nogueira* \\ Universidade Federal de Minas Gerais (UFMG), Belo Horizonte - MG, Brasil \\ Bréscia França Nonato** \\ Universidade Federal de Minas Gerais (UFMG), Belo Horizonte - MG, Brasil \\ Gustavo Meirelles Ribeiro *** \\ Universidade Federal de Ouro Preto (UFOP), Ouro Preto - MG, Brasil \\ Sandra Regina Dantas Flontino ${ }^{* \cdots *}$ \\ Universidade Federal de Minas Gerais (UFMG), Belo Horizonte - MG, Brasil
}

RESUMO: Com base em dados disponibilizados pela própria universidade, o artigo investiga as implicações da adesão da Universidade Federal de Minas Gerais (UFMG) ao Sistema de Seleção Unificada (Sisu). Analisam-se basicamente três aspectos: o grau de eficiência alcançado na ocupação das vagas oferecidas no Sisu pela instituição, considerando-se os fenômenos da não matrícula de alunos aprovados e da evasão e da mudança de curso de parte dos matriculados; a possível diversificação do alunado em termos da origem geográfica; os possíveis efeitos do Sisu e da chamada Lei de Cotas sobre o perfil social dos alunos atendidos pela instituição. $\mathrm{O}$ artigo evidencia que a adesão ao Sisu está produzindo mudanças consideráveis na universidade. Argumenta-se que, para compreendê-las, é necessário considerar que o sistema induz os candidatos a um comportamento mais estratégico e que os submete a uma forte concorrência, inclusive no interior das diferentes modalidades de cotas.

Palavras-chave: Acesso ao Ensino Superior, ações afirmativas, política de cotas, Sistema de Seleção Unificada (Sisu).

\footnotetext{
"Doutor em Educação pela Universidade Federal de Minas Gerais. Professor Associado de Sociologia da Educação da Faculdade de Educação da UFMG. E-mail: < cmmn@uol.com.br > .

" Doutoranda e Mestre em Educação pela Universidade Federal de Minas Gerais. Professora dos anos iniciais da Educação Básica e do Ensino Superior. E-mail: < brescianonato@yahoo.com.br > .

"** Mestre em Patologia pela Universidade Federal de Minas Gerais. Professor Adjunto da Escola de Medicina da Universidade Federal de Ouro Preto. Doutorando em Educação: Sociologia da Educação: escolarização e desigualdades sociais. Faculdade de Educação da Universidade Federal de Minas Gerais. E-mail:<gustavomeirelles@uol.com.br >.

"*** Mestre em Educação: Sociologia da Educação: escolarização e desigualdades sociais pela Universidade Federal de Minas Gerais (UFMG). Professora de Sociologia na rede pública estadual de ensino de Minas Gerais. E-mail:<sandrauab@gmail.com >.
} 


\section{PROMISES AND LIMITS: SISU AND ITS IMPLEMENTATION AT THE FEDERAL UNIVERSITY OF MINAS GERAIS}

ABSTRACT: Based upon data provided by the university itself, this paper investigates the implications of the adhesion to the Unified Selection System (Sisu) by Universidade Federal de Minas Gerais (UFMG). The analysis considers three aspects. The first one is the degree of efficiency achieved in the occupation of the vacancies offered in Sisu by the university, considering the phenomena of the non-enrollment of approved students, the dropouts, and the changing courses by the enrolled students. The second one is the possible diversification of the student body, considering their geographical origin. Finally, the third one is the possible effects of Sisu and the so-called "Quota Law" (a form of affirmative action implemented in Brazil) on the social profile of the enrolled students. The article shows the significant changes that Sisu is producing in the university. It points out the need to consider that the system induces applicants to adopt a strategic behavior and that it submits them to a strong competition, even within the different kinds of quotas. Keywords: Access to higher education, affirmative action, quota policy, Unified System Selection (Sisu).

\section{INTRODUCุÃO}

O Sistema de Seleção Unificada (Sisu) foi criado em 2010 pelo governo federal, como alternativa aos vestibulares realizados até então, de forma descentralizada, pelas instituições públicas de Ensino Superior (BRASIL, 2010). Embora não existisse uma obrigatoriedade de adesão ao sistema, ele foi paulatinamente adotado pela grande maioria das universidades, institutos federais de educação tecnológica e por algumas instituições estaduais.

O Sisu apresentaria, supostamente, três vantagens básicas em relação aos vestibulares. Em primeiro lugar, ele traria um ganho institucional, ao tornar o processo de ocupação das vagas mais barato e mais eficiente. A redução dos custos estaria associada à eliminação dos gastos de cada instituição com a realização de seu próprio vestibular. A maior eficiência na ocupação das vagas decorreria, por sua vez, da facilitação do acesso a elas por parte de estudantes de todo o país. Por meio da plataforma online do Sisu, os estudantes tomariam conhecimento e poderiam se candidatar a qualquer vaga disponível em qualquer instituição participante, sem a necessidade de se prepararem para vestibulares específicos e sem os custos envolvidos na participação nesses diferentes processos seletivos, incluindo o deslocamento para 
a realização de provas. Essa facilitação do acesso poderia minimizar um problema tradicional do sistema de Ensino Superior brasileiro: a existência de um número significativo de vagas ociosas em certos cursos e instituições. Em segundo lugar, e diretamente relacionado ao ponto anterior, o Sisu teria a vantagem de propiciar maior mobilidade geográfica aos estudantes, ampliando as trocas acadêmicas e culturais e a própria integração do país. A oportunidade de se candidatar a vagas em todo o território nacional, sem a necessidade de realização de diferentes vestibulares, estimularia um número maior de indivíduos a se deslocar para estudar fora da sua região de origem. Em terceiro lugar, é preciso destacar o possível efeito de inclusão social do Sisu. Em relação a esse ponto, vale inicialmente registrar a possibilidade aberta aos mais pobres de se candidatarem a cursos e instituições que seriam inacessíveis pelos próprios custos, já mencionados, implicados na participação em diferentes vestibulares. Talvez ainda mais importante do que isso seja a articulação do Sisu com a lei de reserva de vagas (Lei $n^{\circ}$ 12.711/2012), conhecida como Lei de Cotas (BRASIL, 2012). A partir de 2016, quando se completou a fase de implementação dessa lei, pelo menos cinquenta por cento das vagas oferecidas pelo Sisu para cada curso, em cada instituição, passou a ser reservada para alunos que fizeram o Ensino Médio em escolas públicas. ${ }^{1}$

Metade dessas vagas, ou seja, no mínimo vinte e cinco por cento do total, deve ser destinada especificamente para alunos da rede pública com renda familiar per capita inferior a um salário mínimo e meio. A lei prevê ainda que, dentro dos dois conjuntos de cotas assim estabelecidos, seja garantido um percentual de vagas para pretos, pardos e indígenas correspondente à proporção desses grupos, indicada pelo Instituto Brasileiro de Geografia e Estatística (IBGE), na população da unidade da federação em que se encontre a instituição.

Sinteticamente, é possível dizer, portanto, que o Sisu teria três vantagens em relação aos vestibulares tradicionais: 1) ampliaria a eficiência institucional ao baratear o processo de seleção de alunos e melhorar a ocupação das vagas; 2) aumentaria a mobilidade geográfica dos estudantes brasileiros; 3) traria maior inclusão de alunos pertencentes a grupos sub-representados no Ensino Superior brasileiro - basicamente, oriundos de escolas públicas, filhos de famílias de baixa renda, pobres, pretos, pardos e indígenas.

Este artigo se propõe a discutir criticamente essas três promessas relacionadas ao Sisu por meio da análise de uma série de dados relativos aos primeiros anos de adesão da Universidade Federal de Minas Gerais (UFMG) ao sistema. ${ }^{2}$ 
Em relação à promessa de maior eficiência institucional, discutiremos, sobretudo, a previsão de uma ocupação mais completa das vagas oferecidas pela instituição. ${ }^{3}$ De fato, após a adoção do Sisu, cresceu muito o número de candidatos inscritos para a UFMG. Esse crescimento foi acompanhado, no entanto, de dois fenômenos inesperados. Em primeiro lugar, um aumento significativo do número de aprovados que não efetivam suas matrículas, obrigando a universidade a convocar um contingente grande de alunos após a primeira chamada, o que ocasionou atrasos no processo de ocupação inicial das vagas. Em segundo lugar, um aumento considerável do percentual de ingressantes que abandonam a instituição ainda no primeiro período dos seus cursos, gerando dificuldades adicionais para a universidade relativas à ocupação das vagas que se tornam prematuramente ociosas. Como discutiremos no corpo do artigo, esses dois fenômenos parecem associados à própria lógica de funcionamento do Sisu, que indiretamente estimula a escolha, por parte dos candidatos, do curso que é possível, dada sua nota no Exame Nacional do Ensino Médio (Enem), e não daquele verdadeiramente preferido.

Em relação à promessa do ingresso de um número maior de estudantes oriundos de outras regiões do país, os dados também são contraditórios. Como veremos, houve um aumento significativo de inscritos de outras partes do território nacional. O número de estudantes de fora de Minas Gerais que efetivamente se matriculou na instituição não cresceu, no entanto, na mesma proporção, permanecendo relativamente baixo. Mais uma vez, para entender essa aparente contradição é necessário considerar as regras de funcionamento do Sisu. Por um lado, é dada aos alunos a oportunidade de se candidatar ao curso que quiserem, em qualquer lugar do Brasil; por outro lado, não são garantidas as condições objetivas para sua subsistência fora do seu local de origem, o que seria fundamental para aqueles com uma situação social menos favorável. Mesmo que haja a possibilidade real de o estudante ser beneficiado pela assistência estudantil após ingressar na universidade, até o momento da matrícula, esse não tem nenhuma garantia em relação a isso.

Finalmente, no que concerne à promessa de maior inclusão, os dados relativos à UFMG mostram que o perfil geral do alunado da universidade durante o período considerado se alterou menos do que se poderia imaginar; em parte, possivelmente, pelo fato de que a instituição já adotava um sistema de bonificação que contemplava alunos de escolas públicas, estudantes de origem social mais baixa, pretos, pardos e indígenas. De qualquer forma, como veremos, é possível identificar 
mudanças mais expressivas quando se analisa o perfil do alunado por curso. Assim, nos cursos mais seletivos da universidade houve um aumento considerável de alunos de escolas públicas. Mesmo nesse caso, no entanto, observaremos que esse aumento se deu basicamente com o ingresso de mais candidatos oriundos de estabelecimentos federais de Ensino Médio, que tradicionalmente, até mesmo pelo fato de aplicarem processos seletivos de ingresso, tendem a atender a alunos com um perfil social e escolar mais elevado do que os perfis das demais escolas públicas. No corpo do artigo, discutiremos que os limites no processo de inclusão via Sisu parecem relacionados ao fato de que as notas de corte para os cursos mais seletivos continuaram elevadas, mesmo no interior das cotas.

Discutiremos, na primeira parte deste estudo, a lógica de funcionamento do Sisu e como ela afeta as decisões individuais. $\mathrm{Na}$ segunda parte, descreveremos inicialmente o processo de adesão da UFMG ao sistema e sua adequação às cotas. Em seguida, servindo de dados da própria universidade, analisaremos em que medida as três promessas relacionadas ao Sisu, mencionadas, foram cumpridas durante a fase de implementação do sistema na instituição. $\mathrm{O}$ artigo termina com algumas considerações sobre o atual cenário.

\section{O SISU E AS DECISÕES INDIVIDUAIS}

Para compreender a inovação no acesso ao Ensino Superior introduzida pelo Sisu parece necessário analisar com mais detalhes as próprias regras de funcionamento do sistema e o modo como os indivíduos reagem a elas. Como observam Abreu e Carvalho (2014), o Sisu funciona basicamente como um mecanismo de matching, ou seja, de pareamento ou ajustamento entre vagas ofertadas por instituições de todo o país e indivíduos, também situados em todo o território nacional, interessados em ocupá-las. Esse ajustamento se realiza em diferentes etapas. Uma primeira, chamada pelos autores de etapa "pré-jogo", na qual os indivíduos sinalizam quais são seus dois cursos preferidos e o sistema faz e divulga simulações sobre suas probabilidades de serem aprovados. Uma segunda, denominada "jogo de matching", na qual são feitas as escolhas definitivas e os indivíduos são ou não aprovados. E a terceira, o "ajuste de matching", na qual os indivíduos aprovados em primeira chamada apenas para sua segunda opção e aqueles não aprovados em nenhuma das duas opções decidem se entrarão ou não na lista de espera para as próximas chamadas de suas primeiras opções. 
Iniciado o período de inscrição, as instituições divulgam numa plataforma online as vagas que estão disponíveis para os diferentes cursos, dentro de cada uma das cinco modalidades estabelecidas pela lei de reserva de vagas: livre concorrência; egressos de escola pública, independentemente da renda; egressos de escola pública, autodeclarados pretos, pardos ou indígenas, independentemente da renda; egressos de escola pública com renda familiar mais baixa; egressos de escola pública com renda familiar mais baixa e autodeclarados pretos, pardos e indígenas. Já no primeiro dia de inscrição, os indivíduos que fizeram o Enem no ano imediatamente anterior têm a oportunidade de manifestarem, na mesma plataforma, sua opção por uma das modalidades de concorrência e seu interesse por dois cursos de uma mesma ou de duas instituições, um em primeira e outro em segunda opção. A partir do número de indivíduos interessados nas vagas disponíveis para os cursos de cada instituição em cada modalidade de concorrência e de suas notas no Enem, ${ }^{4}$ o sistema calcula a nota mínima que seria necessária para a aprovação. Os indivíduos que manifestaram interesse nessas vagas são também classificados em função de sua nota no Enem ${ }^{5}$. Na madrugada do segundo dia de inscrições, o sistema divulga a nota de corte prevista e cada candidato tem também acesso à sua classificação provisória nos cursos por ele indicados. As notas mínimas e a classificação, divulgadas nesse momento, funcionam apenas como simulação, não havendo qualquer garantia de que se manterão ao final das inscrições. De qualquer forma, com base nessas informações, os indivíduos podem redefinir suas opções em função da probabilidade maior ou menor que vislumbram de serem selecionados para os cursos e instituições que inicialmente indicaram. A partir dessas redefinições, o sistema calcula mais uma vez a nota de corte prevista para cada curso e indica a classificação do indivíduo nos cursos indicados por ele. Esse processo se repete ao longo dos dias de inscrição, dando aos candidatos novas oportunidades de ajustarem suas escolhas às suas reais possibilidades de aprovação. Essa etapa é chamada por Abreu e Carvalho (2014) de "pré-jogo".

Ao final desse período, os interessados são obrigados a indicar, de maneira definitiva, uma primeira e uma segunda opção de curso. É com base nessas últimas indicações que o sistema calcula a nota de corte efetiva para os cursos de cada instituição dentro de cada modalidade de concorrência e define a lista de aprovados. Esse seria o "jogo de matching" propriamente dito (ABREU; CARVALHO, 2014).

Divulgados os resultados, os candidatos aprovados, seja para os cursos que indicaram como primeira ou segunda opção, são 
chamados para se matricularem nas instituições de Ensino Superior. Aqueles aprovados para sua primeira opção de curso que não se matricularem perdem automaticamente o direito de ocuparem qualquer vaga. Aqueles que não foram aprovados em nenhuma de suas opções de curso ou que o foram apenas na segunda podem participar de uma lista de espera, organizada pelas próprias instituições, para sua primeira opção de curso ${ }^{6}$. As vagas não ocupadas pelos candidatos aprovados e convocados pelo próprio sistema são redirecionadas para aqueles que manifestaram interesse em participar das listas de espera. Com base nessas listas, as instituições realizam sucessivas chamadas, visando ao preenchimento da totalidade das vagas ofertadas. Essa é a etapa de "ajuste de matching".

Para se entender o comportamento dos candidatos diante do Sisu é preciso considerar, em primeiro lugar, que eles já entram no sistema com uma nota, definida pelo seu desempenho no Enem. No vestibular, o indivíduo se candidata a um curso e, em seguida, realiza um exame no qual precisa alcançar nota suficiente para ser aprovado. O Sisu inverte essa dinâmica: o indivíduo já tem uma nota e se candidata a dois cursos (em primeira e segunda opção) em relação aos quais ele já sabe com muito mais segurança do que no vestibular, dadas as simulações feitas na etapa inicial do Sisu, suas possibilidades reais de ser aprovado.

Essa diminuição do nível de incerteza tende, logicamente, a estimular uma escolha estratégica pelo curso possível. O candidato não tem como se iludir sobre ser aprovado num determinado curso quando as simulações da primeira etapa do Sisu sugerem sistematicamente o contrário. Além disso, ao mesmo tempo em que sonhos impossíveis são desfeitos, opções mais viáveis são apresentadas. $O$ candidato não precisa, assim, sair do processo com o peso de ter sido simplesmente reprovado. Ao contrário, o sistema indiretamente o estimula, por meio das simulações iniciais, a ajustar suas preferências originais ao que é objetivamente possível de modo a ser aprovado, mesmo que não no curso ou instituição mais desejados.

Como já foi bastante documentado pela literatura (PAUL; SILVA, 1998; BRAGA; PEIXOTO; BOGUTCHI, 2001; PEIXOTO; BRAGA, 2004), essa escolha pelo possível também ocorre no vestibular, porém de forma bem mais limitada. Nesse caso, os indivíduos se orientam pela informação do que foi a nota de corte dos diferentes cursos nos anos anteriores - informação bem mais insegura do que a oferecida na primeira fase do Sisu - e pela expectativa, também incerta, sobre qual será seu próprio desempenho nas provas do vestibular escolhido. A partir dessas informações relativamente 
precárias também é possível adequar minimamente as preferências às possibilidades reais. Para muitos, esse ajustamento, no entanto, demora anos. $\mathrm{O}$ indivíduo tenta várias vezes o vestibular para determinado curso até se convencer de que não é possível e mudar seus objetivos. Com o Sisu, esse ajustamento pode ser feito de forma muito mais precisa, rápida e sem custos adicionais.

Vale notar que o Sisu abre também a possibilidade de ajustamentos em direção contrária. Um indivíduo que, pela nota de corte dos anos anteriores e por suas expectativas de desempenho no vestibular, poderia abrir mão da opção por um curso mais seletivo, pode se surpreender, descobrindo, na primeira fase do Sisu, que tem condições de ser aprovado. Nesse aspecto, o sistema pode favorecer especialmente candidatos com uma origem social mais baixa e que, nos termos de Bourdieu (2013a, 2013b), aprenderam, em função de seu habitus de classe, a terem aspirações escolares mais modestas.

Se a escolha pelo possível pode ter esse lado positivo, não se pode esquecer que majoritariamente ela significa o afastamento do candidato em relação às suas preferências reais. A opção por um curso possível em detrimento do curso efetivamente desejado pode se traduzir na não matrícula após a aprovação ou mesmo na evasão logo após o ingresso na universidade, dois fenômenos que parecem estar se acentuando, como veremos em relação à UFMG.

Cabe ainda salientar que, embora o Sisu reduza, por meio das simulações iniciais, o grau de incerteza das decisões individuais, os candidatos continuam operando num ambiente de informação limitada e, portanto, de risco. Como já foi dito, as simulações da primeira etapa não garantem que o candidato será aprovado num curso em que ele estava bem classificado até o dia anterior e nem asseguram que ele não poderia ser aprovado em determinado curso que parecia inacessível. Como todos os indivíduos estão revendo suas apostas continuamente até os últimos minutos da etapa inicial, a nota de corte definitiva e a classificação efetiva dos candidatos são até certo ponto incertas. Além disso, os candidatos não sabem o que ocorrerá na fase de ajuste de matching, ou seja, quantos candidatos aprovados para o curso de sua preferência realizarão efetivamente suas matrículas e, portanto, quais suas chances reais de serem convocados a partir da lista de espera.

\section{ENTRE PROMESSAS E LIMITES: A IMPLEMENTAC̣ÃO DO SISU NA UFMG}

Como mostra o Quadro 1, a adesão da UFMG ao Sisu em 2014 foi precedida da incorporação progressiva da nota do Enem ao 
vestibular. Com o Sisu, a universidade passou a realizar dois processos seletivos anuais, ${ }^{7}$ diferentemente do que ocorria antes, quando havia apenas um vestibular com duas entradas ao ano.

Quase todas as vagas antes oferecidas por meio do vestibular passaram a ser vinculadas ao novo sistema, tendo como exceção os cursos de educação a distância, a Licenciatura em Educação do Campo e a Formação Intercultural para Educadores Indígenas. No caso dos cursos que exigem habilidades específicas ${ }^{8}$, a universidade utiliza o Sisu apenas na primeira etapa.

QUADRO 1 - Formas de processos seletivos utilizados pela UFMG entre 2010 e 2015

\begin{tabular}{|c|c|c|c|c|c|c|}
\hline & $\begin{array}{c}\text { Vestibular } \\
2010\end{array}$ & $\begin{array}{c}\text { Vestibular } \\
2011\end{array}$ & $\begin{array}{c}\text { Vestibular } \\
2012\end{array}$ & $\begin{array}{c}\text { Vestibular } \\
2013\end{array}$ & $\begin{array}{l}\text { Sisu } \\
2014\end{array}$ & $\begin{array}{l}\text { Sisu } \\
2015\end{array}$ \\
\hline $1^{\mathrm{a}}$ etapa & $\begin{array}{c}\text { Provas da } \\
\text { UFMG } \\
\text { (64 pontos) }\end{array}$ & $\begin{array}{l}\text { Média das } \\
5 \text { provas do } \\
\text { Enem } \\
\text { (64 pontos) }\end{array}$ & $\begin{array}{c}\text { Média das } \\
4 \text { provas do } \\
\text { Enem } \\
\text { (64 pontos) }\end{array}$ & $\begin{array}{l}\text { Média das } \\
4 \text { provas } \\
\text { do Enem } \\
\text { (100 pontos) }\end{array}$ & $\begin{array}{c}\text { Fim da } \\
1^{\text {a }} \text { etapa } \\
\text { (exceto nos } \\
\text { cursos de } \\
\text { habilidades) }\end{array}$ & $\begin{array}{c}\text { Fim da } \\
1^{\text {a }} \text { etapa } \\
\text { (exceto nos } \\
\text { cursos de } \\
\text { habilidades) }\end{array}$ \\
\hline $2^{\mathrm{a}}$ etapa & $\begin{array}{c}\text { Provas } \\
\text { específicas } \\
\text { da UFMG } \\
\text { (96 pontos) }\end{array}$ & $\begin{array}{c}\text { Provas } \\
\text { específicas } \\
\text { da UFMG } \\
\text { (96 pontos) }\end{array}$ & $\begin{array}{l}\text { Provas da } \\
\text { UFMG + } \\
\text { redação do } \\
\text { Enem } \\
\text { (80 pontos } \\
+16 \text { pontos) }\end{array}$ & $\begin{array}{l}\text { Provas da } \\
\text { UFMG + } \\
\text { redação do } \\
\text { Enem } \\
\text { (125 pontos } \\
+25 \text { pontos) }\end{array}$ & $\begin{array}{c}\text { Média das } \\
5 \text { provas do } \\
\text { Enem } \\
\text { (em torno de } \\
1.000 \text { pontos) }\end{array}$ & $\begin{array}{c}\text { Média das } \\
5 \text { provas do } \\
\text { Enem } \\
\text { (em torno de } \\
1.000 \text { pontos) }\end{array}$ \\
\hline Total & $\begin{array}{c}100 \% \text { de } \\
\text { provas da } \\
\text { UFMG }\end{array}$ & $\begin{array}{c}40 \% \text { de } \\
\text { provas do } \\
\text { Enem }+60 \% \\
\text { de provas da } \\
\text { UFMG }\end{array}$ & $\begin{array}{c}50 \% \text { de } \\
\text { provas do } \\
\text { Enem }+50 \% \\
\text { de provas da } \\
\text { UFMG }\end{array}$ & $\begin{array}{c}50 \% \text { de } \\
\text { provas do } \\
\text { Enem }+50 \% \\
\text { de provas da } \\
\text { UFMG }\end{array}$ & $\begin{array}{c}100 \% \text { de } \\
\text { provas do } \\
\text { Enem }\end{array}$ & $\begin{array}{c}100 \% \text { de } \\
\text { provas do } \\
\text { Enem }\end{array}$ \\
\hline $\begin{array}{l}\text { Política de } \\
\text { ação } \\
\text { afirmativa }\end{array}$ & $\begin{array}{c}\text { Bônus: } \\
\text { 10\% e 15\% }\end{array}$ & $\begin{array}{c}\text { Bônus: } \\
\text { 10\% e 15\% }\end{array}$ & $\begin{array}{c}\text { Bônus: } \\
\text { 10\% e 15\% }\end{array}$ & Cotas: $12,5 \%$ & Cotas: $25 \%$ & Cotas: $37,5 \%$ \\
\hline
\end{tabular}

Fonte: UFMG, 2015 a.

O quadro apresentado mostra que, além da transição do vestibular para o Sisu, a universidade viveu nos últimos anos a passagem de um programa de ação afirmativa baseado em bônus para um sistema de cotas. Vigente entre 2009 e 2012, o programa de bônus acrescentava $10 \%$ à nota de alunos que cursaram os últimos sete anos da Educação Básica na escola pública e 15\% à nota daqueles que, além disso, se autodeclaravam negros. ${ }^{9}$

A partir de 2013, com a aprovação da Lei Federal no 12.711, a UFMG encerrou a política de bônus e começou a implementar, de modo gradual, a reserva de vagas por curso. No processo seletivo de 
2013, 12,5\% das vagas foram destinados a candidatos que fizeram o Ensino Médio em escolas públicas, oriundos de famílias de baixa renda, pretos, pardos e indígenas. Em 2014, esse percentual foi elevado para 25\%, passando, em 2015, para 37,5\%. Em 2016, com a finalização do processo de implementação da política de cotas, chegaremos a $50 \%$ de vagas reservados.

A seguir, analisaremos como as três promessas principais associadas ao Sisu estão se realizando na UFMG nesses primeiros anos de adoção do sistema. A discussão será feita considerando que em 2015 a política de cotas ainda não estava plenamente implementada.

\section{MAIOR EFICIÊNCIA NA OCUPACุÃO DAS VAGAS?}

Como possível efeito da entrada da UFMG no Sisu, observouse um grande aumento no número de inscrições nos processos seletivos, a partir do primeiro semestre de 2014. O Gráfico 1 mostra esse crescimento, considerando-se todos os cursos ofertados.

\section{GRÁFICO 1}

Número de candidatos inscritos nos processos seletivos da UFMG entre 2009 e 2015

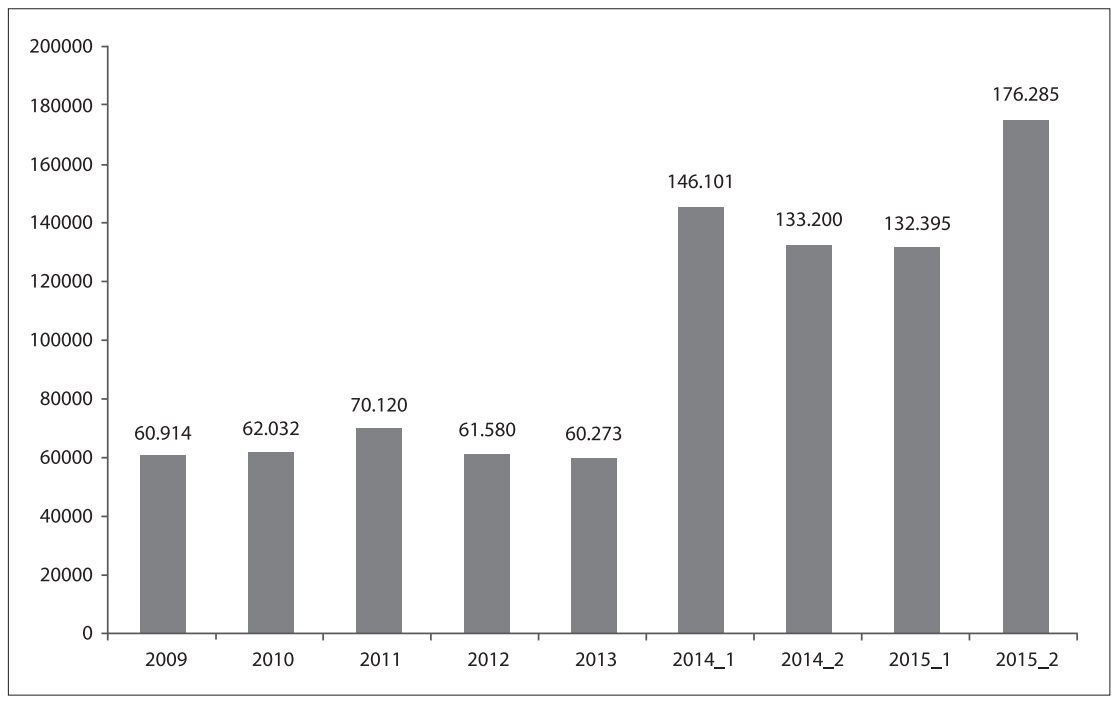

Fonte: UFMG, 2015a, 2015b.

O aumento do número de inscritos poderia sugerir que se resolveria finalmente o problema da ocupação das chamadas vagas ociosas na universidade. Entretanto, conforme já mencionado, dois novos fenômenos passaram a ser observados. Em primeiro lugar, 
grande parte dos aprovados e convocados na primeira chamada não se matriculou. Para preencher suas vagas, a universidade passou a ter que convocar, em chamadas subsequentes, um número muito maior de candidatos, segundo as listas divulgadas pelo Departamento de Registro e Controle Acadêmico da UFMG (DRCA) (UFMG, 2015c).

Em segundo lugar, como mostra o Gráfico 2, observou-se, a partir da adoção do Sisu, um aumento expressivo da evasão, já no primeiro período do curso.

\section{GRÁFICO 2}

Alunos que mudaram de curso/evadiram no $1^{\circ}$ período entre 2011 e 2014 na UFMG (\% do total de matriculados)

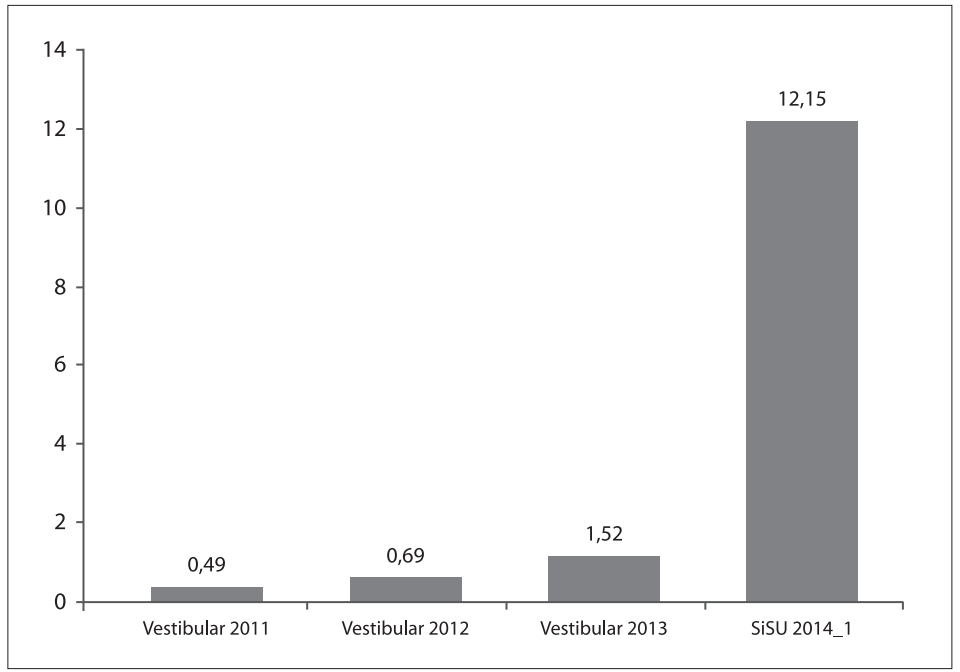

Fonte: UFMG, 2015a.

O aumento do percentual de alunos convocados que não se matriculou e o aumento das taxas de evasão podem ter várias explicações. Como abordado anteriormente, é possível que as opções feitas pelos candidatos no Sisu não correspondam, em alguma medida, às escolhas que fariam caso não tivessem acesso às simulações relativas às notas de corte e à ordem de classificação no período de inscrição. Também não se pode esquecer que a facilidade para se inscrever a partir de qualquer ponto do país não significa a eliminação dos custos e dificuldades para se estudar fora do local de residência. Nesse sentido, como veremos posteriormente, o aumento do número de inscritos de fora de Minas Gerais na UFMG não é acompanhado de elevação equivalente no percentual de matriculados de fora do estado. É importante considerarmos também que continuam existindo, paralelamente ao 
Sisu, outras formas de acesso ao Ensino Superior, como vestibulares específicos em instituições públicas que não aderiram ao sistema e a possibilidade de bolsas de estudo e financiamento estudantil em instituições privadas por meio do Programa Universidade para Todos (Prouni) e do Fundo de Financiamento Estudantil (Fies). Essas alternativas podem se tornar atraentes para alunos que não obtiveram acesso a nenhum curso ou aos cursos de sua preferência por meio do Sisu, e mesmo para aqueles que foram bem-sucedidos, mas que encontraram dificuldades práticas para se deslocar ou se manter na instituição para a qual foram selecionados.

Os dados da UFMG permitem supor ainda que parte da evasão registrada não significa um simples abandono da instituição pelos alunos, mas uma estratégia de mudança de curso. Boa parte dos evadidos retorna à UFMG utilizando a mesma nota do Enem. Assim, no Gráfico 3, podemos observar um percentual expressivo de mudança de curso mediante novo processo seletivo entre as entradas do primeiro e segundo semestre de 2014. Mesmo na passagem de 2014 para 2015, o percentual de alunos que reingressou na UFMG por novo processo seletivo foi bastante superior ao que se observava em anos anteriores. Mesmo que nesse caso seja necessário fazer novo Enem, os custos e as dificuldades do processo são bastante inferiores às que existiam quando era necessário se submeter a novo vestibular.

\section{GRÁFICO 3}

Percentual de mudanças de curso mediante processo seletivo do ano/semestre seguinte na UFMG

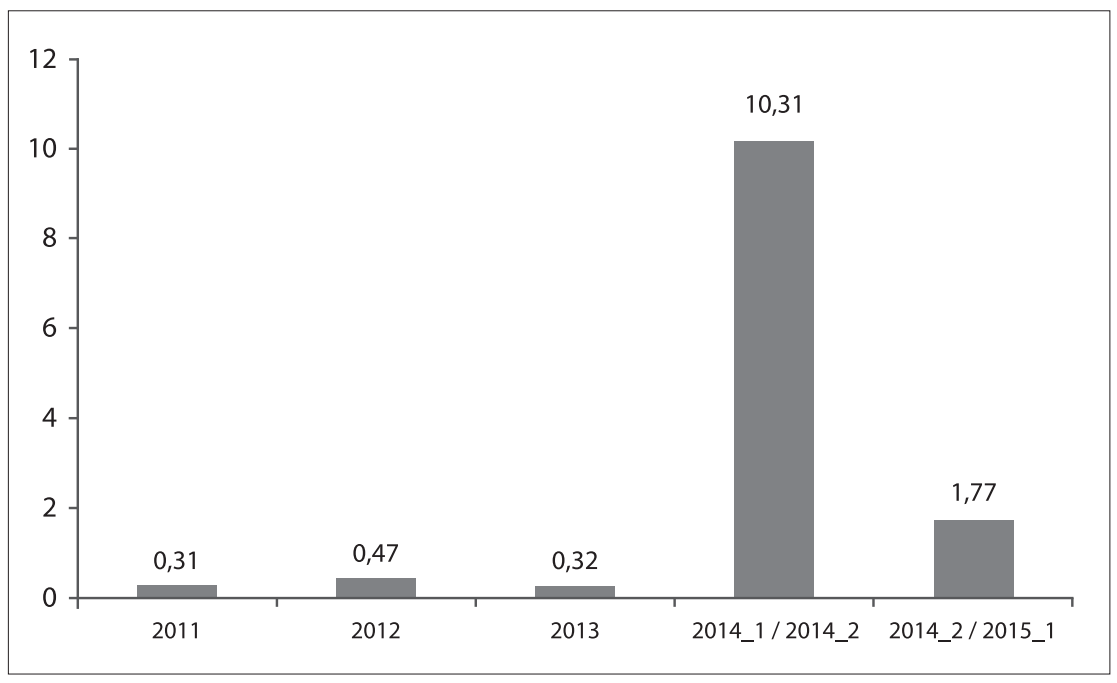

Fonte: UFMG, 2015a. 
No que se refere ao uso do Sisu no meio do ano como estratégia para mudança de curso é preciso também considerar que o nível de seletividade na primeira edição anual do Sisu tende a ser maior do que na segunda edição, até mesmo pelo fato de parte dos candidatos com maiores notas no Enem já ter sido aprovada no começo do ano. Em 2014, por exemplo, a média da nota de corte de todos os cursos ofertados pela UFMG foi $4 \%$ mais alta na primeira edição do Sisu, enquanto a média da nota máxima foi 2,2\% mais alta nessa mesma edição (UFMG, 2015d). ${ }^{10}$

Do ponto de vista da eficiência na ocupação das vagas disponíveis na universidade, cabe considerar que a facilidade para se inscrever no Sisu e a possibilidade de utilização da mesma nota do Enem para uma segunda edição do Sisu no meio do ano geraram efeitos perversos consideráveis. Por um lado, como vimos, houve um aumento das taxas de não matrícula, acarretando aumento do número de chamadas para preenchimento das vagas remanescentes e atraso na entrada de alunos no primeiro período de curso. Por outro lado, o aumento da evasão e das mudanças de curso ampliou o problema das vagas ociosas nos semestres seguintes dos cursos. Este último problema mostra-se particularmente grave no caso dos cursos de menor prestígio social, que têm perdido boa parte dos alunos inicialmente matriculados e que não recebem fluxos significativos de novos alunos evadidos de outros cursos.

\section{MAIOR MOBILIDADE ESTUDANTIL?}

Uma das promessas do Ministério da Educação (MEC) em relação ao Sisu era a ampliação da mobilidade estudantil, entendida como a possibilidade de um aluno de um estado ou região se inscrever em instituições de Ensino Superior localizadas em outro estado ou região do país servindo-se apenas da nota do Enem. Essa forma de seleção nacional traria benefícios para os estudantes de baixa renda, por meio da diminuição de custos com vestibulares, além de um crescimento no acesso às vagas das universidades mais distantes dos grandes centros (LUZ; VELOSO, 2014). Além disso, a comodidade do sistema levaria, segundo o MEC, a uma maior integração nacional, favorecendo os intercâmbios culturais, a socialização e um maior conhecimento das realidades de cada canto do país.

Os dados da UFMG (TABELA 1) mostram, no entanto, que a origem do alunado permaneceu maciçamente mineira após a adoção do Sisu, embora o número de estudantes de outros estados tenha passado de 4\% em 2011, para 7\% em 2015. 
TABELA 1 - Local de origem do alunado da UFMG

\begin{tabular}{|l|c|c|c|c|}
\hline & Até 2012 & $\mathbf{2 0 1 3}$ & $\mathbf{2 0 1 4}$ & $\mathbf{2 0 1 5}$ \\
\hline Belo Horizonte & $64 \%$ & $65 \%$ & $64 \%$ & $61 \%$ \\
\hline Região Metropolitana de Belo Horizonte & $17 \%$ & $17 \%$ & $14 \%$ & $15 \%$ \\
\hline Interior de Minas Gerais & $16 \%$ & $14 \%$ & $15 \%$ & $17 \%$ \\
\hline Outros estados & $4 \%$ & $4 \%$ & $6 \%$ & $7 \%$ \\
\hline
\end{tabular}

Fonte: UFMG, 2015a

É interessante observar algumas mudanças consideráveis no percentual de inscritos e de matriculados de outras regiões antes e depois da adoção do Sisu pela UFMG. Segundo relatório da PróReitoria de Graduação (UFMG, 2015a), em 2012, com o sistema de vestibular, o número de inscritos para esta universidade no estado do Amazonas era de 19 estudantes. Com o Sisu, em 2014, esse número saltou para 1.674 estudantes. Já em relação aos alunos efetivamente matriculados, não se registrou nenhuma matrícula do estado do Amazonas em 2012; em 2014, com o Sisu, ocorreram duas matrículas. Outro exemplo, também da região Norte, é o estado do Pará, que contava com 115 estudantes inscritos em 2013 e passou a ter 2.979 inscritos no Sisu de 2014. Três alunos efetivamente se matricularam na UFMG em 2012 (vestibular) e esse número passou para seis em 2014, mesmo número de 2015. Já os nove estados da região Nordeste possuíam 1.532 inscrições em 2012 e esse valor subiu para 11.925 com a primeira edição do Sisu em 2014. Já na extremidade oposta do nosso território temos, por exemplo, o estado do Rio Grande do Sul com 18 inscritos no vestibular de 2012 e 1.503, em 2014; este estado saltou de uma matrícula na UFMG em 2012 para cinco, em 2014.

Os dados deixam claro, portanto, que o aumento do número de candidatos de outras regiões inscritos na UFMG, após a adoção do Sisu, não foi acompanhado de uma elevação igualmente expressiva no número de matriculados de fora de Minas Gerais. As figuras a seguir mostram isso de forma contundente. Enquanto a origem geográfica dos candidatos (FIGURA 1) se espalha por todo o país após a adoção do Sisu, a origem geográfica dos matriculados permanece basicamente a mesma (FIGURA 2). 
FIGURA 1 - Mapa de alunos inscritos na UFMG entre os anos de 2012 e 2015

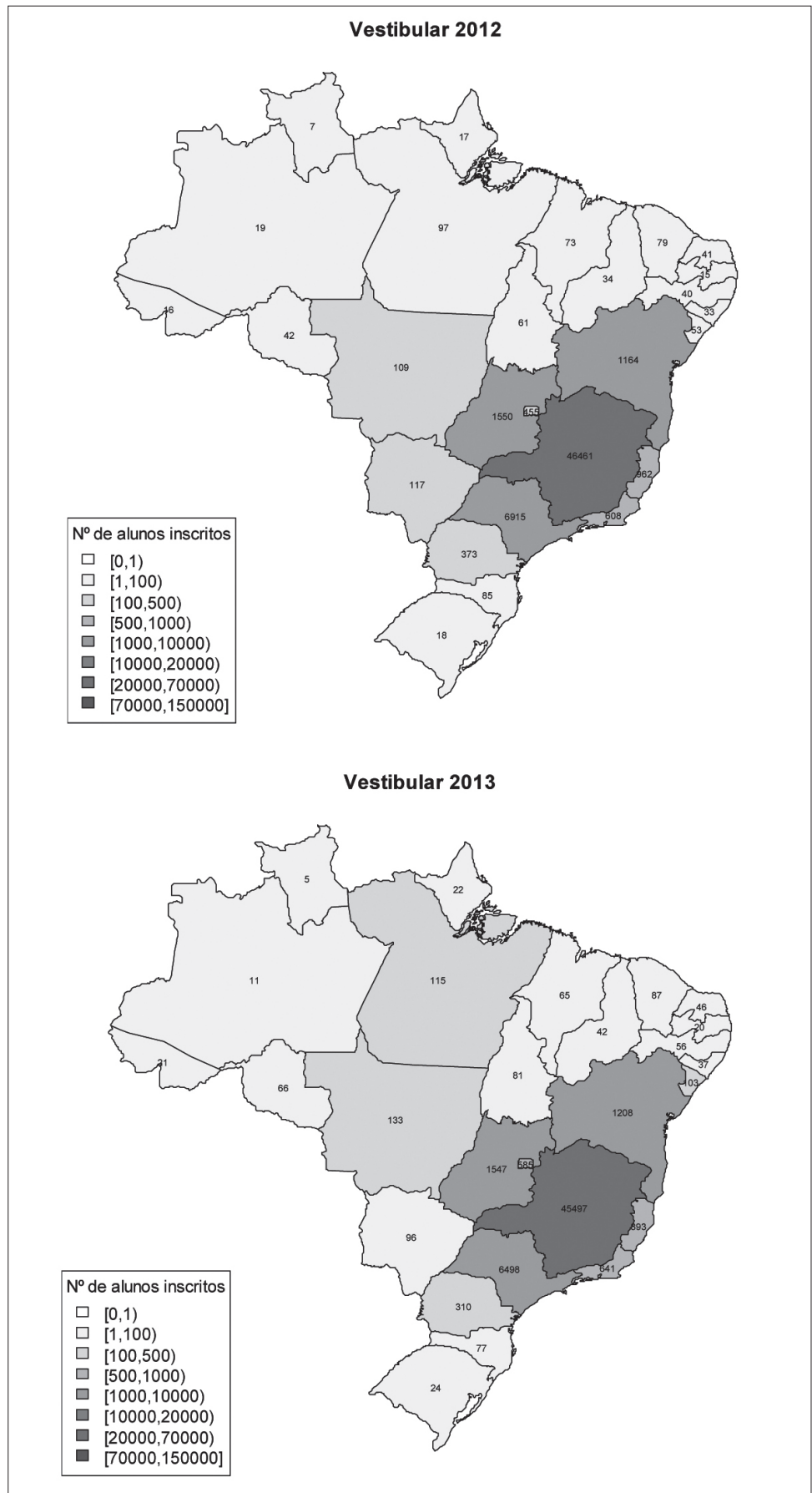

Fonte: UFMG, 2015a. 
FIGURA 1 - Mapa de alunos inscritos na UFMG entre os anos de 2012 e 2015 (continuação)

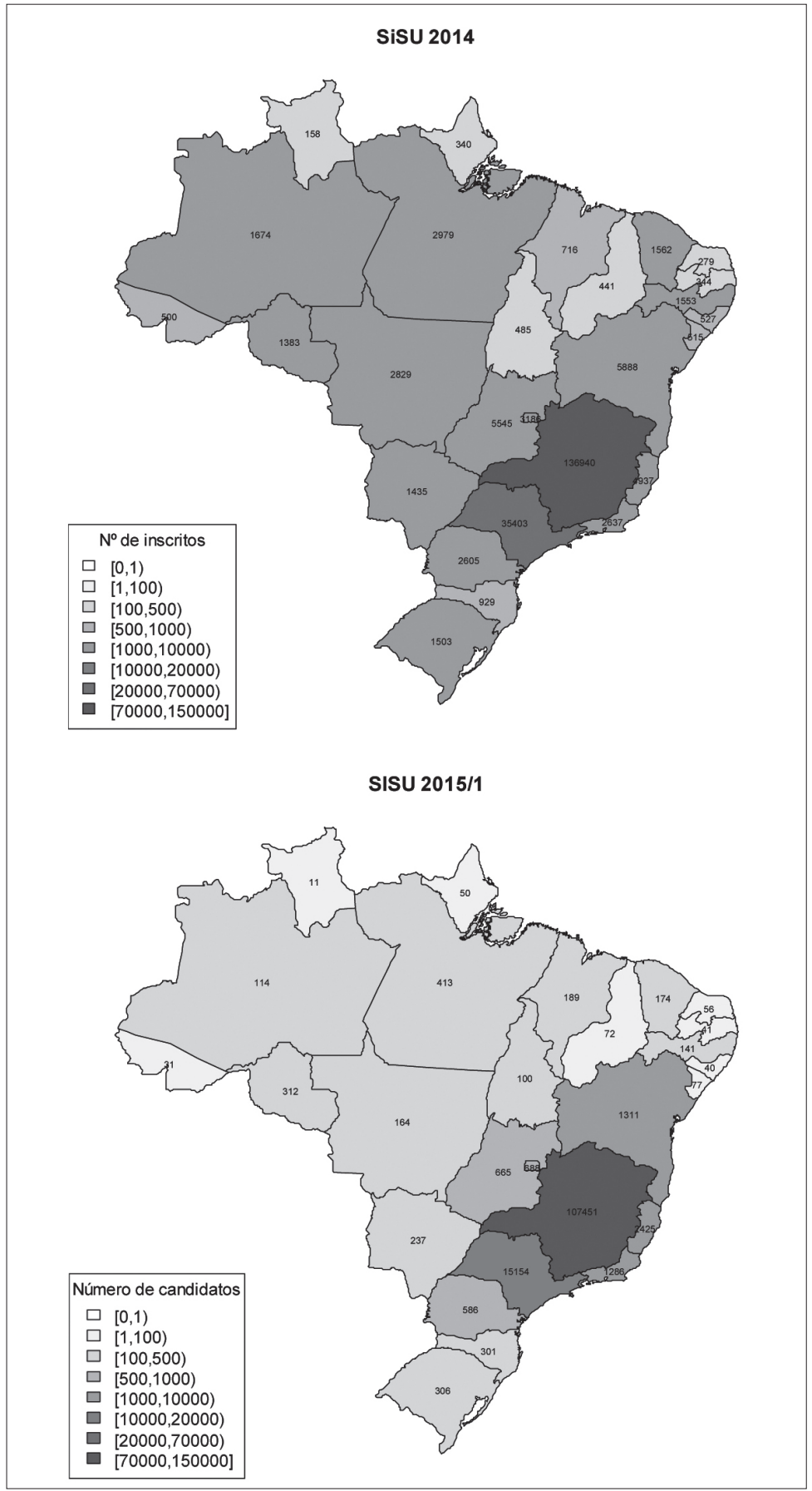

Fonte: UFMG, 2015a. 
FIGURA 2 - Mapa dos alunos matriculados na UFMG entre os anos de 2012 e 2015

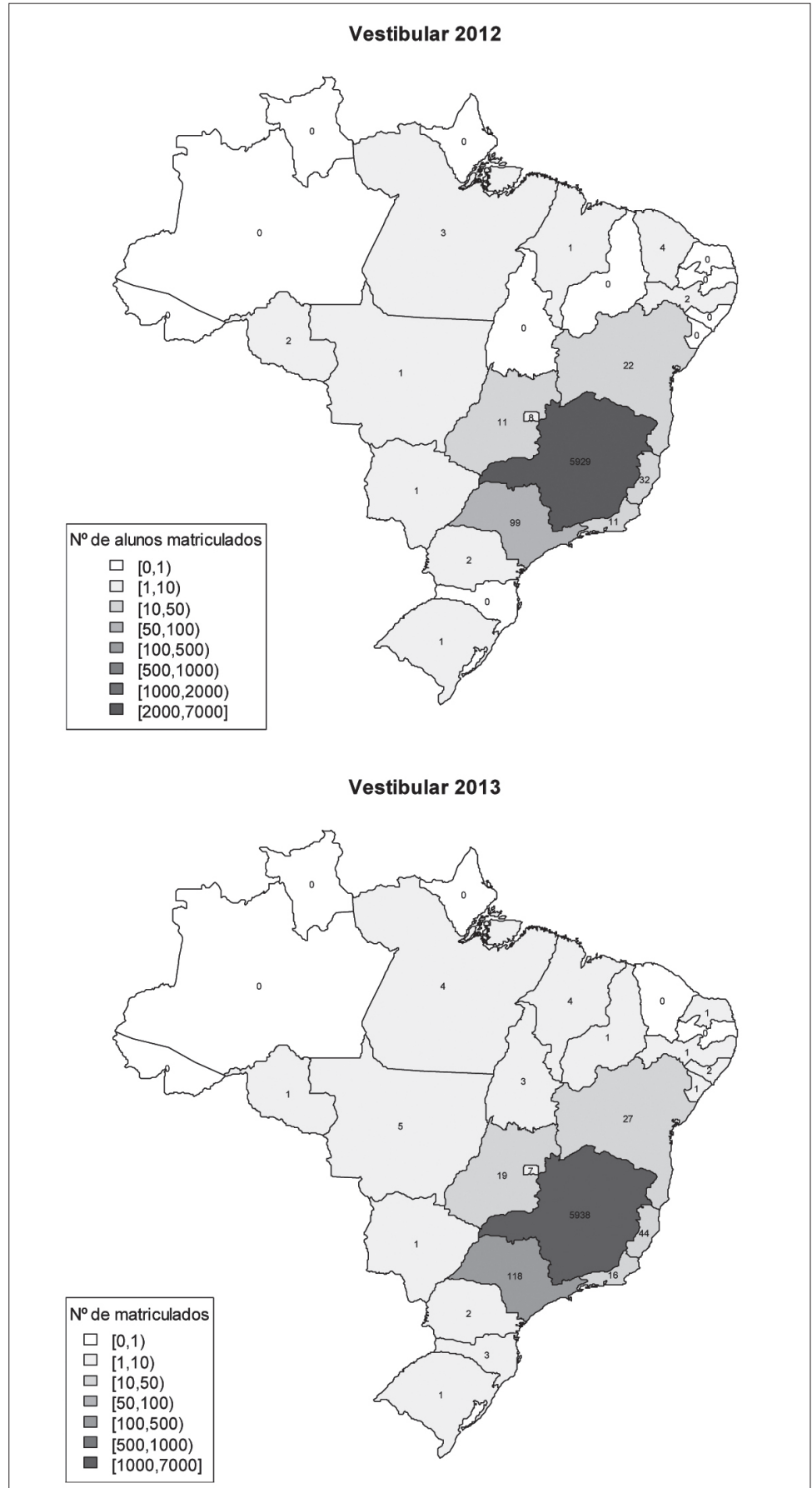

Fonte: UFMG, 2015a. 
FIGURA 2 - Mapa dos alunos matriculados na UFMG entre os anos de 2012 e 2015 (continuação).

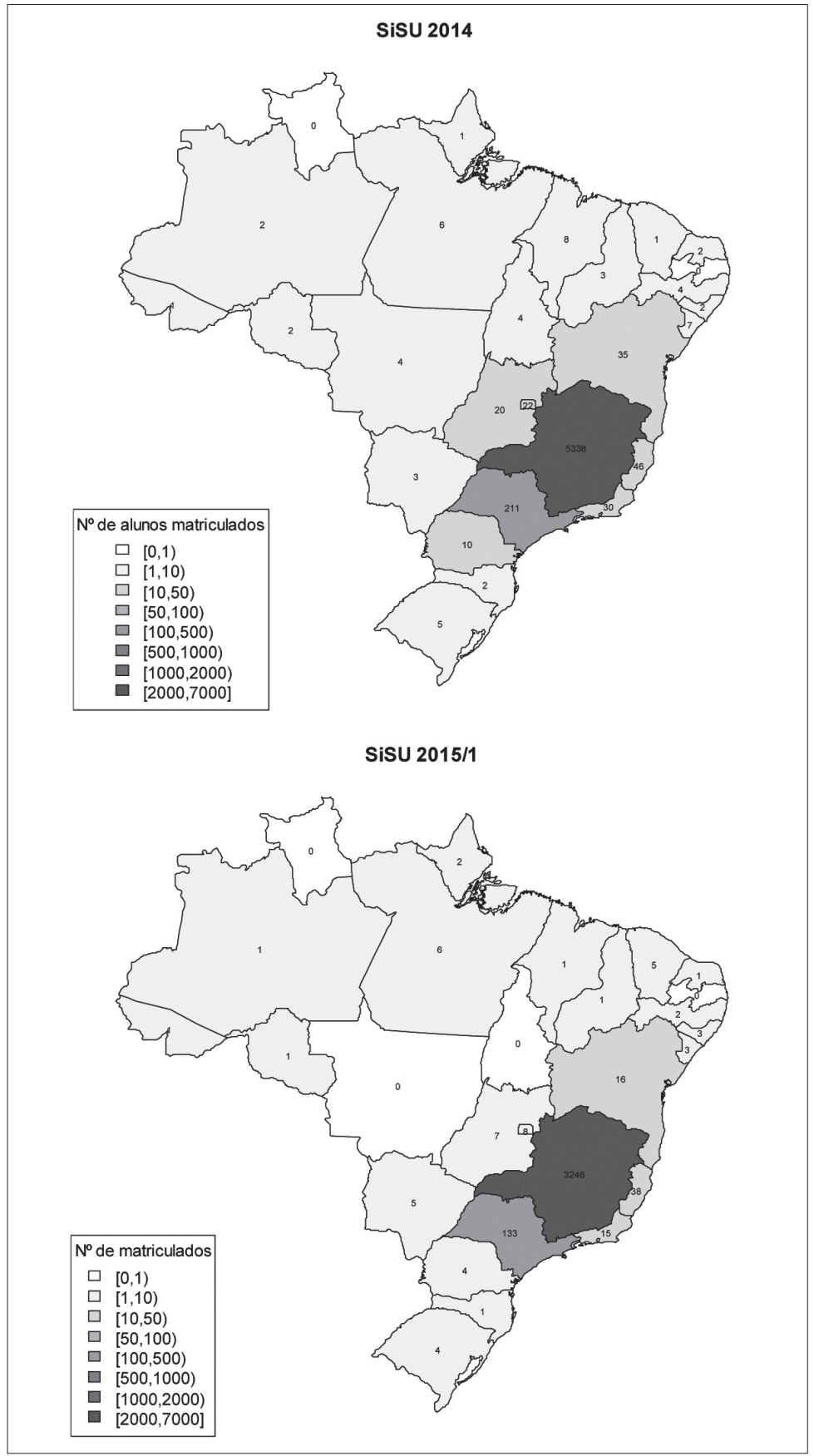

Fonte: UFMG, 2015a. 
Para se entender as razões dessa discrepância entre o aumento exponencial de inscritos e o crescimento modesto no número de inscritos de outros estados é preciso considerar, em primeiro lugar, que o número total de candidatos inscritos na UFMG passou de 61.580 em 2012 para 146.101 em 2014, após a adoção do Sisu. Assim, é possível dizer que o Sistema de Seleção Unificada propicia um maior número de inscrições, mas amplia, concomitantemente, a concorrência e o número de pessoas que não conseguem ingressar na universidade, pelo menos nos cursos de maior prestígio social.

Conforme já discutimos, é preciso considerar também que a lógica de funcionamento do Sisu, especialmente com as simulações da etapa inicial de "pré-jogo", estimula uma escolha estratégica pelo curso possível. Diante da evidência da impossibilidade de ter acesso ao curso que realmente prefere, o aluno pode se inscrever e até ser aprovado em outro curso, sem que de fato pretenda cursá-lo. O fato de o sistema oferecer a possibilidade de uma segunda opção de curso acentua ainda mais esse fenômeno. Se a primeira opção já não corresponde necessariamente às verdadeiras preferências do candidato, visto que esse foi levado a se adaptar às suas possibilidades reais de aprovação, isso é ainda mais provável no caso da segunda opção.

Finalmente, para se compreender o número grande de inscritos e o número baixo de matriculados oriundos de outros estados é necessário pensar criticamente sobre o discurso de democratização do acesso que o Sisu proporciona: se com o sistema de vestibulares, a opção por fazer provas em universidades de várias localidades do país estava reservada aos estudantes de maior poder aquisitivo, a mobilidade estudantil pósSisu em grande medida também só é efetivamente acessível àqueles que possuem renda para se deslocar - e se manter - em universidades distantes da sua moradia. Há uma série de restrições objetivas que fazem a promessa da mobilidade não ser tão realizável quanto deveria. O que Luz e Veloso (2014) chamam de "elitismo educacional" continua a existir, uma vez que estudantes de menor poder aquisitivo dependerão das políticas de assistência estudantil, que ainda são incipientes e não dão conta de atender plenamente às necessidades dos acadêmicos migrantes. Vale observar que o período entre a aprovação no Sisu e a mudança para o novo local de estudo é muito curto e que o aluno não tem a certeza de que terá a assistência estudantil que lhe possibilitaria a efetiva permanência no curso superior ${ }^{11}$. A UFMG procurou amenizar esse problema fazendo, já no ato da matrícula, a análise socioeconômica dos aprovados e a seleção dos alunos que necessitariam de algum tipo de assistência estudantil. Já é um avanço, visto que, antes, o estudante ficava esperando até por um semestre por essa avaliação. As dificuldades, no entanto, não deixam de existir. 


\section{MAIOR INCLUSÃO SOCIAL?}

De modo geral podemos dizer que o Sisu traz consigo pelo menos dois aspectos que podem ser considerados positivos do ponto de vista da inclusão de novos grupos sociais ao Ensino Superior. O primeiro deles, conforme abordado anteriormente, se refere à possibilidade de ampliação do acesso em função da diminuição dos custos que antes seriam necessários para participação em múltiplos processos seletivos. Deixa de ser necessário que o candidato disponha de recursos financeiros para inscrição e deslocamento entre diferentes instituições públicas federais do país para concorrer a vagas nos cursos de graduação.

O segundo, que supostamente possui maior efeito inclusivo, diz respeito à obrigatoriedade da articulação do Sisu com a Lei de Cotas. Em função dessa obrigatoriedade, esperava-se uma visível alteração no perfil social dos estudantes das universidades federais.

No caso da UFMG, quando se considera a origem escolar do conjunto de alunos matriculados entre 2010 e 2015 (TABELA 2), é possível dizer, no entanto, que não houve alterações radicais na destinação das vagas. No período considerado, as duas mudanças mais significativas foram o aumento do percentual de egressos de escolas particulares e a redução daqueles estudantes de escola pública durante os anos de 2013 e 2014. Essas mudanças, revertidas em 2015, parecem associadas ao fim dos bônus raciais e sociais e sua substituição por cotas inicialmente muito modestas, 12,5\% em 2013 e 25\% em 2014.

\section{TABELA 2}

Escola onde 0 estudante cursou, integralmente ou na sua maior parte, 0 Ensino Médio ${ }^{12}$

\begin{tabular}{|c|c|c|c|c|c|c|c|c|c|c|c|c|}
\hline \multicolumn{13}{|c|}{ GERAL } \\
\hline & \multicolumn{2}{|c|}{2010} & \multicolumn{2}{|c|}{2011} & \multicolumn{2}{|c|}{2012} & \multicolumn{2}{|c|}{2013} & \multicolumn{2}{|c|}{2014} & \multicolumn{2}{|c|}{2015} \\
\hline $\begin{array}{l}\text { Escola } \\
\text { particular }\end{array}$ & 3.522 & $53,5 \%$ & 3.407 & $51,8 \%$ & 3.331 & $51,0 \%$ & 3.675 & $55,5 \%$ & 3.529 & $57,6 \%$ & 3.207 & $51,7 \%$ \\
\hline $\begin{array}{l}\text { Escola } \\
\text { pública }\end{array}$ & 3.053 & $46,3 \%$ & 3.147 & $47,9 \%$ & 3.193 & $48,9 \%$ & 2.921 & $44,1 \%$ & 2.566 & $41,9 \%$ & 2.981 & $48,1 \%$ \\
\hline $\begin{array}{l}\text { Escola } \\
\text { estadual }\end{array}$ & 2.053 & $67,2 \%$ & 2.179 & $69,2 \%$ & 2.218 & $69,5 \%$ & 2.063 & $70,6 \%$ & 1.512 & $58,9 \%$ & 1.816 & $60,9 \%$ \\
\hline $\begin{array}{l}\text { Escola } \\
\text { federal }\end{array}$ & 628 & $20,6 \%$ & 607 & $19,3 \%$ & 623 & $19,5 \%$ & 593 & $20,3 \%$ & 875 & $34,1 \%$ & 988 & $33,1 \%$ \\
\hline $\begin{array}{l}\text { Escola } \\
\text { municipal }\end{array}$ & 372 & $12,2 \%$ & 361 & $11,5 \%$ & 352 & $11,0 \%$ & 265 & $9,1 \%$ & 179 & $7,0 \%$ & 177 & $5,9 \%$ \\
\hline Curso livre & 14 & $0,2 \%$ & 19 & $0,3 \%$ & 11 & $0,2 \%$ & 21 & $0,3 \%$ & 20 & $0,3 \%$ & 12 & $0,2 \%$ \\
\hline $\begin{array}{l}\text { Não } \\
\text { respondeu }\end{array}$ & 0 & $0 \%$ & 0 & $0 \%$ & 0 & $0 \%$ & 0 & $0 \%$ & 8 & $0,1 \%$ & 1 & $0,0 \%$ \\
\hline Total & 6.589 & $100 \%$ & 6.573 & $100 \%$ & 6.535 & $100 \%$ & 6.617 & $100 \%$ & 6.123 & $100 \%$ & 6.201 & $100,0 \%$ \\
\hline
\end{tabular}

Fonte: Elaborado pelos autores a partir de dados de questionários PROGRAD/UFMG (2015a). 
Outra mudança que pode ser identificada na tabela é uma elevação considerável das matrículas de alunos de escolas federais a partir de 2014. Essa também parece relacionada à substituição dos bônus pela Lei de Cotas. Enquanto para o primeiro era necessário ter feito os últimos sete anos da Educação Básica na rede pública para ter direito ao bônus, a Lei de Cotas exige apenas o Ensino Médio.

Outro ponto relevante é a heterogeneidade das escolas públicas brasileiras do Ensino Básico e Ensino Médio. De modo geral, as instituições federais possuem melhor infraestrutura e corpo profissional mais qualificado. Além disso, sabe-se que parte considerável dos estudantes que ingressam nessas escolas altamente seletivas possui uma origem social mais elevada. Assim, o aumento do percentual de ingressantes oriundos dessas instituições, em detrimento dos egressos das escolas estaduais e municipais, põe em dúvida o alcance dos efeitos de inclusão obtidos a partir da adoção da Lei de Cotas em articulação com o Sisu. Essa questão se torna ainda mais relevante se considerarmos que, segundo dados do Censo da Educação 2015 (BRASIL, 2015), em 2014, 87\% das matrículas no Ensino Médio estavam no setor público; desses, 97\% das matrículas no Nível Médio estão nas redes estaduais e apenas 3\% em escolas municipais e federais. Há, portanto, uma grande distorção agravada com a adoção da Lei de Cotas nas possibilidades de acesso à universidade pelos estudantes do setor público, quando se consideram as redes de ensino de onde se originam.

Para se avaliar os efeitos, em termos de inclusão social, da articulação entre o Sisu e a Lei de Cotas é preciso considerar também a possibilidade de que esteja ocorrendo uma superseleção no interior das cotas. Para a grande massa de egressos do setor público foram reservados, na UFMG: 25\% das vagas em 2014; 37,5\% em 2015 e se chegará ao limite máximo de 50\% em 2016. Temos, portanto, uma grande quantidade de candidatos oriundos do setor público concorrendo a um número limitado de vagas reservadas. Nesse caso, é compreensível que sejam selecionados, dentro de cada modalidade de concorrência, apenas aqueles com perfil social e escolar mais elevado.

Isso talvez explique uma situação que tem sido observada desde o início da implementação do Sisu e que pouco se alterou com o aumento percentual das cotas: em vários cursos, a nota mínima para aprovação tem sido maior em algumas modalidades de cotas do que para a ampla concorrência. ${ }^{13}$ Esperava-se que a Lei de Cotas contemplasse pessoas que não obtivessem nota para aprovação na ampla concorrência, isso porque se pressupunha um desempenho mais baixo dos cotistas. Entretanto, de um total de 78 cursos ofertados no Sisu 2015/1 período 
letivo, 46 tiveram a nota de corte, em pelo menos uma das modalidades de cota, superior à da ampla concorrência (UFMG, 2015a).

Do ponto de vista da inclusão social, o risco que se tem é que os estudantes que estejam ingressando por meio das cotas, sobretudo nos cursos mais seletivos e de maior prestígio social, sejam a elite dos subgrupos por eles representados e que os candidatos tradicionalmente excluídos da universidade estejam continuando a sê-lo.

De qualquer forma, nossas análises têm evidenciado que o Sisu e, em especial, o sistema de cotas atuam de modo muito diferenciado em cada curso. Considerando os três cursos a seguir (TABELAS 3, 4, 5 e 6), buscamos evidenciar, a partir do tipo de escola frequentada, situações variadas que têm ocorrido após a adesão da universidade ao Sisu e sua adequação à Lei de Cotas.

O curso de Medicina, tradicionalmente ocupado por estudantes de escolas particulares, apresentava em 2010 um percentual de $38 \%$ de alunos oriundos de escolas públicas, o qual foi retomado em 2015. Entretanto, é interessante observar que, em 2010, a maior parte das matrículas era de alunos provenientes da rede estadual, o que não ocorreu em 2015, já que a maior parte desse percentual (64\%) se refere a instituições da rede federal de ensino, aquelas que, como já exposto, são responsáveis por menos de 3\% das matrículas do Ensino Médio. ${ }^{14}$

TABELA 3

Medicina: escola onde 0 estudante cursou, integralmente ou na sua maior parte, o Ensino Médio

\begin{tabular}{|l|c|c|c|c|c|c|c|c|c|c|c|c|}
\hline \multicolumn{10}{|c|}{ MEDICINA } \\
\hline $\begin{array}{l}\text { Escola } \\
\text { particular }\end{array}$ & 200 & $\mathbf{2 0 1 0}$ & \multicolumn{2}{|c|}{2011} & \multicolumn{2}{|c|}{2012} & \multicolumn{2}{|c|}{2013} & \multicolumn{2}{|c|}{2014} & \multicolumn{2}{|c|}{2015} \\
\hline $\begin{array}{l}\text { Escola } \\
\text { pública }\end{array}$ & 120 & $38 \%$ & 82 & $26 \%$ & 69 & $22 \%$ & 51 & $16 \%$ & 87 & $28 \%$ & 121 & $38 \%$ \\
\hline $\begin{array}{l}\text { Escola } \\
\text { estadual }\end{array}$ & 64 & $53 \%$ & 51 & $62 \%$ & 24 & $35 \%$ & 20 & $39 \%$ & 23 & $26 \%$ & 38 & $31 \%$ \\
\hline $\begin{array}{l}\text { Escola } \\
\text { federal }\end{array}$ & 53 & $44 \%$ & 26 & $32 \%$ & 43 & $62 \%$ & 30 & $59 \%$ & 62 & $71 \%$ & 78 & $64 \%$ \\
\hline $\begin{array}{l}\text { Escola } \\
\text { municipal }\end{array}$ & 3 & $3 \%$ & 5 & $6 \%$ & 2 & $3 \%$ & 1 & $2 \%$ & 2 & $2 \%$ & 5 & $4 \%$ \\
\hline $\begin{array}{l}\text { Curso livre } \\
\text { Não }\end{array}$ & 0 & $0 \%$ & 0 & $0 \%$ & 0 & $0 \%$ & 0 & $0 \%$ & 0 & $0 \%$ & 0 & $0 \%$ \\
\hline respondeu & 0 & $0 \%$ & 0 & $0 \%$ & 0 & $0 \%$ & 0 & $0 \%$ & 0 & $0 \%$ & 0 & $0 \%$ \\
\hline Total & 320 & $100 \%$ & 318 & $100 \%$ & 319 & $100 \%$ & 322 & $100 \%$ & 316 & 100 & 319 & $100 \%$ \\
\hline
\end{tabular}

Fonte: Elaborado pelos autores a partir de dados de questionários PROGRAD/UFMG (2015a). 
No curso de Enfermagem, os dados apresentam uma situação bem distinta. Esse curso, historicamente, sempre recebeu grande contingente de estudantes provenientes de escolas públicas estaduais. Como observado na Tabela 3, houve uma inversão no percentual de matrículas após a adesão ao Sisu. Estudantes provenientes de escolas particulares apresentaram um aumento expressivo de sua representatividade nos anos de 2014 e 2015. Algumas hipóteses podem ser formuladas para esse fenômeno. Uma delas é que, devido à ampliação da concorrência por meio do Sisu, o processo de ingresso tenha se tornado mais seletivo. Outra hipótese complementar a essa se refere ao fato de o Sisu permitir ao estudante verificar, durante o processo, suas reais chances de aprovação em determinados cursos e refazer suas escolhas em função do possível. Com isso, é provável que muitos estudantes oriundos das escolas particulares, e que pretendiam inicialmente ingressar em cursos mais concorridos, como, por exemplo, Medicina, tenham se redirecionado para o curso de Enfermagem, menos seletivo e também pertencente à área de saúde.

TABELA 4

Enfermagem: escola onde 0 estudante cursou, integralmente ou na sua maior parte, 0 Ensino Médio

\begin{tabular}{|l|c|c|c|c|c|c|c|c|c|c|c|c|}
\hline \multicolumn{10}{|c|}{ ENFERMAGEM } \\
\hline $\begin{array}{l}\text { Escola } \\
\text { particular }\end{array}$ & 46 & $48 \%$ & 46 & $48 \%$ & 36 & $37 \%$ & 41 & $43 \%$ & 60 & $64 \%$ & 49 & $53 \%$ \\
\hline $\begin{array}{l}\text { Escola } \\
\text { pública }\end{array}$ & 50 & $52 \%$ & 50 & $52 \%$ & 61 & $62 \%$ & 55 & $57 \%$ & 34 & $36 \%$ & 44 & $47 \%$ \\
\hline $\begin{array}{l}\text { Escola } \\
\text { estadual }\end{array}$ & 38 & $76 \%$ & 42 & $84 \%$ & 48 & $79 \%$ & 44 & $80 \%$ & 28 & $82 \%$ & 37 & $84 \%$ \\
\hline $\begin{array}{l}\text { Escola } \\
\text { federal }\end{array}$ & 5 & $10 \%$ & 1 & $2 \%$ & 6 & $10 \%$ & 6 & $11 \%$ & 2 & $6 \%$ & 6 & $14 \%$ \\
\hline $\begin{array}{l}\text { Escola } \\
\text { municipal }\end{array}$ & 7 & $14 \%$ & 7 & $14 \%$ & 7 & $11 \%$ & 5 & $9 \%$ & 4 & $12 \%$ & 1 & $2 \%$ \\
\hline Curso livre & 0 & $0 \%$ & 0 & $0 \%$ & 1 & $1 \%$ & 0 & $0 \%$ & 0 & $0 \%$ & 0 & $0 \%$ \\
\hline $\begin{array}{l}\text { Não } \\
\text { respondeu }\end{array}$ & 0 & $0 \%$ & 0 & $0 \%$ & 0 & $0 \%$ & 0 & $0 \%$ & 0 & $0 \%$ & 0 & $0 \%$ \\
\hline Total & 96 & $100 \%$ & 96 & $100 \%$ & 98 & $100 \%$ & 96 & $100 \%$ & 94 & 100 & 93 & $100 \%$ \\
\hline
\end{tabular}

Fonte: Elaborado pelos autores a partir de dados de questionários PROGRAD/UFMG (2015a). 
O terceiro exemplo refere-se ao curso de Direito. Esse curso, assim como Medicina, era ocupado majoritariamente por estudantes oriundos de escolas particulares. Porém, o percentual de ocupação no que se refere à origem escolar dos estudantes sempre teve variação de acordo com o turno. Entre as especificidades de cada turno, cabe salientar que o Direito diurno tradicionalmente apresentava-se com maior percentual de estudantes advindos de escolas particulares, situação que não se alterou com a política do bônus, mas que vem sofrendo alteração em função da Lei de Cotas.

Em 2010, os estudantes provenientes de escolas particulares ocupavam 83\% das vagas do curso de Direito diurno; em 2015 esse percentual se reduziu para $60 \%$. Em relação à participação relativa de alunos provenientes de cada rede no interior do setor público, observase, assim como ocorreu com Medicina, uma maior participação dos egressos das escolas federais.

\section{TABELA 5}

Direito diurno: escola onde 0 estudante cursou, integralmente ou na sua maior parte, 0 Ensino Médio

\begin{tabular}{|l|c|c|c|c|c|c|c|c|c|c|c|c|}
\hline \multicolumn{10}{|c|}{ DIREITO DIURNO } \\
\hline $\begin{array}{l}\text { Escola } \\
\text { particular }\end{array}$ & 165 & $\mathbf{2 0 1 0}$ & 166 & $83 \%$ & 175 & $88 \%$ & 168 & $43 \%$ & 144 & $72 \%$ & 120 & $60 \%$ \\
\hline $\begin{array}{l}\text { Escola } \\
\text { pública }\end{array}$ & 35 & $18 \%$ & 34 & $17 \%$ & 24 & $12 \%$ & 33 & $57 \%$ & 55 & $28 \%$ & 80 & $40 \%$ \\
\hline $\begin{array}{l}\text { Escola } \\
\text { estadual }\end{array}$ & 18 & $51 \%$ & 20 & $59 \%$ & 6 & $25 \%$ & 13 & $80 \%$ & 22 & $40 \%$ & 33 & $41 \%$ \\
\hline $\begin{array}{l}\text { Escola } \\
\text { federal }\end{array}$ & 16 & $46 \%$ & 12 & $35 \%$ & 18 & $75 \%$ & 20 & $11 \%$ & 27 & $49 \%$ & 46 & $58 \%$ \\
\hline $\begin{array}{l}\text { Escola } \\
\text { municipal }\end{array}$ & 1 & $3 \%$ & 2 & $6 \%$ & 0 & $0 \%$ & 0 & $9 \%$ & 6 & $11 \%$ & 1 & $1 \%$ \\
\hline Curso livre & 0 & $0 \%$ & 0 & $0 \%$ & 0 & $0 \%$ & 0 & $0 \%$ & 0 & $0 \%$ & 0 & $0 \%$ \\
\hline $\begin{array}{l}\text { Não } \\
\text { respondeu }\end{array}$ & 0 & $0 \%$ & 0 & $0 \%$ & 0 & $0 \%$ & 0 & $0 \%$ & 0 & $0 \%$ & 0 & $0 \%$ \\
\hline Total & 200 & $100 \%$ & 200 & $100 \%$ & 199 & $100 \%$ & 201 & $100 \%$ & 199 & 100 & 200 & $100 \%$ \\
\hline
\end{tabular}

Fonte: Elaborado pelos autores a partir de dados de questionários PROGRAD/UFMG (2015a).

O curso de Direito noturno apresenta uma situação diferente do curso diurno. Aparentemente, os primeiros anos de implantação da Lei de Cotas, em conjunto com a adesão ao Sisu, tornaram o 
curso mais seletivo, haja vista que o percentual de egressos de escola particular aumentou de 57\% em 2012 para 75\% em 2013. Nos anos seguintes esse movimento foi, no entanto, em parte, revertido.

\section{TABELA 6}

Direito noturno: escola onde 0 estudante cursou, integralmente ou na sua maior parte, 0 Ensino Médio

\begin{tabular}{|l|c|c|c|c|c|c|c|c|c|c|c|c|}
\hline \multicolumn{10}{|c|}{ DIREITO NOTURNO } \\
\hline $\begin{array}{l}\text { Escola } \\
\text { particular }\end{array}$ & 113 & $57 \%$ & 114 & 575 & 114 & $57 \%$ & 149 & $75 \%$ & 140 & $70 \%$ & 121 & $62 \%$ \\
\hline $\begin{array}{l}\text { Escola } \\
\text { pública }\end{array}$ & 86 & $43 \%$ & 85 & $43 \%$ & 86 & $43 \%$ & 50 & $25 \%$ & 56 & $28 \%$ & 74 & $38 \%$ \\
\hline $\begin{array}{l}\text { Escola } \\
\text { estadual }\end{array}$ & 46 & $53 \%$ & 47 & $55 \%$ & 53 & $62 \%$ & 24 & $48 \%$ & 27 & $48 \%$ & 39 & $53 \%$ \\
\hline $\begin{array}{l}\text { Escola } \\
\text { federal }\end{array}$ & 31 & $36 \%$ & 28 & $33 \%$ & 27 & $31 \%$ & 23 & $46 \%$ & 20 & $36 \%$ & 33 & $45 \%$ \\
\hline $\begin{array}{l}\text { Escola } \\
\text { municipal }\end{array}$ & 9 & $10 \%$ & 10 & $12 \%$ & 6 & $7 \%$ & 3 & $6 \%$ & 9 & $16 \%$ & 2 & $3 \%$ \\
\hline $\begin{array}{l}\text { Curso livre } \\
\text { Não } \\
\text { respondeu }\end{array}$ & 01 & $1 \%$ & 1 & $1 \%$ & 0 & $0 \%$ & 1 & $1 \%$ & 2 & $1 \%$ & 0 & $0 \%$ \\
\hline Total & 200 & $100 \%$ & 200 & $100 \%$ & 200 & $100 \%$ & 200 & $100 \%$ & 199 & 100 & 195 & $100 \%$ \\
\hline
\end{tabular}

Fonte: Elaborado pelos autores a partir de dados de questionários PROGRAD/UFMG (2015a).

O modo como têm se efetivado a implementação da Lei de Cotas e a adesão ao Sisu, por parte da universidade, varia conforme as características de cada curso. A Lei de Cotas apresenta efeitos controversos. Em alguns casos, tem ocorrido um aumento na quantidade de estudantes de escolas públicas de modo geral; em outros, esse aumento tem se dado essencialmente por meio do ingresso de estudantes da rede pública federal de ensino. Há situações, porém, em que apesar da Lei de Cotas se gerou um aumento considerável de matrículas provenientes de estudantes das escolas particulares.

\section{CONSIDERACְÕES FINAIS}

As análises feitas neste artigo com dados sobre o acesso e a permanência dos estudantes na UFMG, após a adoção do Sisu, mostram que parte das expectativas positivas que se tinha em relação 
a esse novo sistema de seleção não tem se cumprido. Em relação à ocupação das vagas oferecidas pela universidade, verificou-se uma elevação significativa da não matrícula de candidatos convocados, gerando a necessidade de sucessivas chamadas e a evasão de um percentual grande de alunos ainda nos primeiros semestres dos cursos, ocasionando uma ampliação das vagas ociosas. Em relação à evasão, os dados da universidade indicam que parte dos alunos volta à universidade em outros cursos. Não se trata, portanto, de um simples abandono, mas de uma estratégia de mudança de curso propiciada pelas próprias regras do Sisu. De qualquer forma, o fato é que a ampliação da não matrícula de convocados, o abandono por parte de estudantes dos primeiros períodos e a intensificação do movimento de mudança de cursos tornaram o processo de ocupação das vagas menos eficiente e estável, exatamente o contrário do que se esperava com o Sisu.

Em relação à ampliação da mobilidade estudantil e ao esperado ingresso na universidade de um número maior de estudantes de outras regiões do país, os dados também mostram algumas surpresas. O que mais chama atenção é que houve uma elevação brutal do número de inscritos de fora de Minas Gerais, mas uma ampliação bem mais modesta do percentual de matriculados de fora do estado. A expectativa de uma diversificação expressiva da origem geográfica dos alunos, que seria propiciada pela facilitação do acesso a estudantes de outras regiões ao processo seletivo via Sisu, foi, assim, parcialmente frustrada.

Finalmente, em relação à promessa de maior inclusão social, que seria garantida pela articulação do Sisu com a chamada Lei de Cotas, os dados sugerem que as mudanças foram, até o momento, menores do que se podia imaginar. Em termos de sua origem escolar (escola pública ou privada de Ensino Médio) o perfil geral do alunado da universidade não sofreu grande alteração. $\mathrm{O}$ único destaque é a elevação significativa da proporção de estudantes oriundos de escolas federais dentro do conjunto daqueles provenientes de escolas públicas. Embora o perfil geral dos estudantes da universidade pareça não ter se alterado tanto, os dados analisados mostram, por outro lado, que estão ocorrendo mudanças significativas conforme os cursos considerados. Enquanto em alguns a participação de egressos de escolas públicas se elevou de forma acentuada, em outros temos um movimento inverso.

As dificuldades para o cumprimento pleno das promessas associadas ao Sisu no âmbito da UFMG não nos conduzem, no entanto, a uma crítica radical ao sistema. Antes de tudo, é preciso considerar que o Sisu, assim como a Lei de Cotas, ainda está em processo de implementação e que, portanto, seus benefícios podem ainda não ter sido plenamente produzidos. Além disso, os dados 
sugerem que as consequências da adoção do Sisu são complexas e diferenciadas conforme os cursos da universidade, o que exigirá análises muito mais detalhadas antes de qualquer avaliação conclusiva sobre suas vantagens e desvantagens.

No âmbito deste artigo, argumentamos que parte dos problemas que estão sendo identificados nessa fase de implementação do Sisu pode estar ligada ao fato de que as próprias regras de funcionamento do sistema estimulam uma escolha estratégica dos cursos por parte dos candidatos. Em função das simulações feitas na fase de inscrição os candidatos são levados a ter uma visão mais realista de suas possibilidades e, consequentemente, a ajustarem suas preferências originais ao que parece efetivamente mais viável. O resultado pode ser a escolha de cursos possíveis, mas que não são os mais desejados pelos candidatos, o que explicaria parte da não matrícula, da evasão e das tentativas de mudança de curso que se têm observado. Esses fenômenos podem ser reforçados ainda pelas próprias facilidades que o Sisu oferece aos candidatos para participarem de um novo processo seletivo. No meio do ano o estudante pode participar de uma segunda edição do Sisu usando a mesma nota do Enem. Ele tem nesse momento uma nova oportunidade para tentar realizar o curso que realmente deseja. Além disso, mesmo a alternativa de fazer novamente o Enem e se submeter a um novo Sisu no final do ano é mais simples e barata do que era, no passado, a opção de se submeter a um novo vestibular.

Ao longo do artigo argumentamos também que os limites na realização de algumas das promessas associadas ao Sisu, especialmente a mobilidade geográfica estudantil e a inclusão de candidatos com uma origem social mais baixa em cursos mais seletivos, estão relacionados com as condições reais dos candidatos para se beneficiarem dessas oportunidades formalmente oferecidas a todos. No caso da mobilidade geográfica isso é muito claro. Por mais que a plataforma online do Sisu ofereça a possibilidade de o candidato se inscrever em qualquer curso de qualquer instituição do país, na prática, poucos têm condições de se deslocar e se manter em locais distantes da residência. Seriam necessários um aprimoramento considerável das políticas de assistência estudantil e uma ampliação da divulgação de informações sobre elas junto aos candidatos no momento da inscrição para que se compensassem, em alguma medida, as desigualdades existentes entre os estudantes no que se refere às suas condições objetivas para se deslocar pelo país. Do mesmo modo, em relação à política de reserva de vagas, é preciso perceber que ela não garante acesso indiscriminado à universidade aos grupos historicamente excluídos. Pelo contrário, no interior de cada um dos segmentos contemplados pelas cotas, tendem a 
ser beneficiados os subgrupos com perfil social e escolar mais elevado. Esse é o caso, por exemplo, da proporção de egressos das escolas federais relativamente aos oriundos das demais escolas públicas. Isso ocorre, em primeiro lugar, porque, de modo geral, o número de vagas reservadas é pequeno em comparação ao total de potenciais beneficiados. Vale ainda ressaltar que até 2015 a concorrência ocorria dentro de cada modalidade de cotas, levando em muitos casos a se ter no interior das cotas uma nota mínima de corte por vezes superior à exigida para a aprovação por meio da ampla concorrência.

Em segundo lugar, não se pode esquecer que continua a existir uma clara hierarquia entre os cursos em termos de seu prestígio social, fazendo com que o nível de concorrência e as notas de corte sejam, em alguns casos, particularmente elevados.

Essa discussão nos revela, mais uma vez, a dificuldade de se evitar que as desigualdades sociais e escolares acumuladas ao longo das trajetórias dos indivíduos se traduzam em novas desigualdades. O Sisu, em articulação com a Lei de Cotas, pode ser considerado um esforço de ampliação da justiça e da equidade no acesso ao Ensino Superior no Brasil. O sistema amplia as oportunidades formais de acesso a cursos e instituições espalhados por todo o país. Além disso, por meio das cotas, trata de forma especial os grupos que se encontram em situação socialmente desfavorável, proporcionando uma competição mais justa pelas vagas oferecidas. Se esses avanços precisam ser reconhecidos, não se pode, por outro lado, desconsiderar a influência persistente das desigualdades já acumuladas sobre as oportunidades de se ascender ao Ensino Superior, em geral, e a certos cursos, em particular.

\section{REFERÊNCIAS}

ABREU, Luís; CARVALHO, José Raimundo. Análise do jogo induzido pelo mecanismo Sisu de alocação de estudantes em universidades. In: ENCONTRO NACIONAL DE ECONOMIA, 42., 9-12 dez. 2014, Natal-RN. Trabalhos... Rio de Janeiro: ANPEC, 2014. Disponível em: <http://www.anpec.org.br/encontro/2014/ submissao/files_I/i8-63b1970 2151c4ea9c41924b9a7a7b9d8.pdf> Acesso em: 6 jan. 2016.

BOURDIEU, Pierre. A escola conservadora: as desigualdades frente à escola e à cultura. In: NOGUEIRA, Maria Alice; CATANI, Afrânio. Escritos de Educação. 14 ed. Petrópolis: Vozes, 2013a, p. 39-64.

BOURDIEU, Pierre. Futuro de classe e causalidade do provável. In: NOGUEIRA, Maria Alice; CATANI, Afrânio. Escritos de Educação. 14 ed. Petrópolis: Vozes, 2013b. p. 89-141.

BRAGA, Mauro M.; PEIXOTO, Maria do C. L.; BOGUTCHI, Tânia F. Tendências da demanda pelo ensino superior: estudo de caso da UFMG. Cadernos de Pesquisa, São Paulo, n. 113, p. 129-152, jul. 2001. 
BRASIL. Portaria Normativa n ${ }^{\circ}$ 2, de 26 de janeiro de 2010. Institui e regulamenta o Sistema de Seleção Unificada, sistema informatizado gerenciado pelo Ministério da Educação, para seleção de candidatos a vagas em cursos de graduação disponibilizadas pelas instituições públicas de educação superior dele participantes. Diário Oficial da União, Brasília, ano 147, n. 18, seção 1, 27 de janeiro de 2010. Disponível em: <http://pesquisa.in.gov.br/imprensa/ jsp $/$ visualiza $/$ index.jsp?jornal $=1 \&$ pagina $=80 \& d a t a=27 / 01 / 2010>$. Acesso em: 7 jan. 2016 .

BRASIL. Lei $\mathrm{n}^{\circ}$ 12.711, de 29 de agosto de 2012. Dispõe sobre o ingresso nas universidades federais e nas instituições federais de ensino técnico de nível médio e dá outras providências. Diário Oficial da União, Brasília, ano 149, n. 169, seção 1, p. 1-2, 30 ago. 2012. Disponível em: <http://pesquisa.in.gov.br/imprensa/jsp/visualiza/index. jsp? jornal=1\&pagina $=1 \&$ data $=30 / 08 / 2012>$. Acesso em: 7 jan. 2016.

BRASIL. Ministério da Educação e Cultura - MEC. Dados Censo 2015. Brasília, 11 de fevereiro de 2015. Disponível em: < http://portal.mec.gov.br/index.php?option=com_doc uman\&view $=$ download\&alias $=17044$-dados-censo-2015-11-02-materia\&Itemid $=30192>$. Acesso em: 6 out. 2015.

LUZ, Jackeline N. N. da; VELOSO, Tereza C. M. A. Sistema de seleção unificada (Sisu): refletindo sobre o processo de seleção. Revista Educação e Fronteiras On-Line, Dourados, v. 4, n. 10, p. 68-83, jan./abr. 2014.

PAUL Jean-Jacques; SILVA, Nelson V. Conhecendo o seu lugar: a auto-seleção na escolha de carreira. Revista Brasileira de Política e Administração da Educação, Brasília, v. 14, n. 1, p. 115-130, jan./jun. 1998.

PEIXOTO, Maria do C. L; BRAGA, Mauro M. Demanda pelo Ensino Superior no Brasil: o caso da UFMG. Educação \& Linguagem, São Bernardo do Campo, v. 7, n. 10, p. 124-149, jul./dez. 2004.

UNIVERSIDADE FEDERAL DE MINAS GERAIS - UFMG. Histórico do bônus na UFMG. Belo Horizonte: UFMG, s.d. Disponível em: <https://www2.ufmg.br/cais/ cais/ home/A-POLITICA-DE-BONUS-NA-UFMG/HISTORICO-DO-BONUS-NAUFMG >. Acesso em: 1 abr. 2017.

UNIVERSIDADE FEDERAL DE MINAS GERAIS - UFMG. Pró-reitoria de Graduação. Mudanças no Ensino de Graduação da UFMG: Análise e Perspectivas. Belo Horizonte: UFMG, 2015a. Disponível em: <https://www.ufmg.br/prograd/ arquivos/acontece/ ApEst.pdf>. Acesso em: 17 ago. 2015.

UNIVERSIDADE FEDERAL DE MINAS GERAIS - UFMG. UFMG lidera inscrições no Sisu. Belo Horizonte: UFMG, 2015b. Disponível em: < http://www.eeffto.ufmg.br/ eeffto/noticias/286/ufmg_lidera_inscricaes_no_Sisu>. Acesso em: 7 maio 2016.

UNIVERSIDADE FEDERAL DE MINAS GERAIS - UFMG. Departamento de Registro e Controle Acadêmico. Sisu/UFMG. [Site]. Belo Horizonte: UFMG, 2015c. Disponível em: <https://www2.ufmg.br/drca/drca/Home/Graduacao/Processos-Seletivos/SisuUFMG >. Acesso em: 7 jan. 2016.

UNIVERSIDADE FEDERAL DE MINAS GERAIS - UFMG. Notas de corte dos cursos da UFMG em 2014 oferecem parâmetros para os candidatos do Sisu 2015. Belo Horizonte: UFMG, 2015d. Disponível em: < https://www.ufmg.br/online/ arquivos/036897.shtml>. Acesso em 7 jan. 2016. 


\section{NOTAS}

${ }^{1}$ Vale observar que a lei prevê um percentual mínimo de reserva de vagas. Nada impede que as instituições adotem políticas de ação afirmativa mais amplas.

${ }^{2}$ Os pesquisadores agradecem à instituição, em especial à Pró-Reitoria de Graduação, por disponibilizar os dados necessários para as análises.

${ }^{3}$ No âmbito deste artigo não discutiremos os ganhos institucionais relativos à redução dos custos com a realização do vestibular tradicional, inclusive por não dispormos de dados suficientes para desenvolvermos uma análise consistente a respeito.

${ }^{4}$ A nota de um mesmo aluno pode variar conforme o curso e a instituição desejados. Isso ocorre porque as instituições podem atribuir pesos diferentes para cada uma das provas do Enem e essa atribuição pode ainda variar em função do curso específico em questão.

${ }^{5}$ A classificação do indivíduo para a sua segunda opção de curso só é calculada e divulgada caso sua classificação para a sua primeira opção de curso indique que ele não seria aprovado.

${ }^{6}$ Vale ressaltar que o candidato aprovado para sua segunda opção de curso mantém o direito de participar da lista de espera para sua primeira opção mesmo que se matricule no curso para o qual foi inicialmente convocado.

${ }^{7}$ No ano de 2016 a UFMG voltou a realizar apenas um processo seletivo para os dois semestres, servindo-se da $1^{a}$ edição do Sisu. Tal mudança ocorreu tendo em vista os problemas identificados nos primeiros anos de implantação do Sisu e que são discutidos neste artigo.

${ }^{8}$ São eles: Artes Visuais, Cinema de Animação e Artes Digitais, Conservação e Restauração de Bens Culturais Móveis, Dança, Design, Design de Moda, Música (Bacharelado e Licenciatura) e Teatro.

${ }^{9}$ A aprovação da política do bônus foi realizada no ano de 2008 pelo Conselho Universitário. Tal política foi resultado da mobilização de grupos internos e externos da universidade que tinham como objetivo a implementação de medidas que tornassem a universidade mais inclusiva. Para saber mais sobre o histórico dessa política, sugerimos a leitura de UFMG (s.d.).

${ }^{10}$ Dados calculados a partir das notas de corte das duas edições do Sisu de 2014 da UFMG, considerando-se apenas os cursos ofertados em ambas as edições. Foge ao escopo deste estudo comparar as diferenças de notas entre as edições por curso.

${ }^{11} \mathrm{O}$ Ministério da Educação destina às instituições participantes do Sisu recursos específicos para a aplicação em programas de assistência estudantil. Tais programas são executados pelas instituições, no entanto, de maneiras diferentes. Cabe, assim, ao candidato o trabalho complexo de buscar informações a respeito nas instituições em que deseja candidatar-se.

${ }^{12}$ Nessas tabelas buscamos apresentar o percentual de matrículas provenientes de escolas públicas e privadas para, em seguida, identificar entre as escolas públicas o percentual ocupado em cada esfera.

${ }^{13}$ Observando essa distorção, a universidade estabeleceu, a partir de 2016, uma nova regra de ingresso. Independentemente de se inscrever para vagas reservadas ou de ampla concorrência, os candidatos serão primeiramente agrupados na ampla concorrência e somente serão incluídos nas vagas destinadas às cotas se não obtiverem pontuação necessária na primeira. As consequências dessa mudança ainda não podem ser avaliadas.

${ }^{14}$ Cabe observar o contraste que se estabelece em relação aos cursos menos concorridos, como é o caso de Pedagogia. Nesse curso, mesmo havendo uma elevação no número de ingressantes de escolas privadas, as matrículas de estudantes provenientes de escolas estaduais são maioria (52\%). 
Submetido: $11 / 03 / 2016$

Aprovado: 06/06/2016

Contato:

Cláudio Marques Martins Nogueira Rua Rio de Janeiro, 1599, apto 1504 - Lourdes Belo Horizonte $|\mathrm{MG}|$ Brasil CEP 30.160-042

\section{ERRATA}

No artigo "PROMESSAS E LIMITES: O SISU E SUA IMPLEMENTAÇÃO NA UNIVERSIDADE FEDERAL DE MINAS GERAIS” EDUR • Educação em Revista. 2017; 33:e161036 DOI: http://dx.doi.org/10.1590/0102-4698161036. NOGUEIRA, Cláudio Marques Martins et al. Educ. rev., Belo Horizonte, v. 33, e161036, 2017. Available from <http://www.scielo.br/scielo.php?script=sci_ arttext\&pid=S0102-46982017000100116\&lng=en\&nrm=iso $>$.

Alteração na nota 2, onde se lê:

“Os pesquisadores agradecem à instituição, em especial à PróReitoria de Graduação, por disponibilizar os dados necessários para as análises."

Leia-se:

"Os pesquisadores agradecem à instituição, em especial à PróReitoria de Graduação, por disponibilizar os dados necessários para as análises, bem como à FAPEMIG - Fundação de Amparo a Pesquisa do Estado de Minas Gerais, responsável pelo financiamento da pesquisa.” 